\title{
Does physical activity lower the risk for metabolic syndrome: a longitudinal study of physically active older women
}

Izabela Zając-Gawlak 1* D, Jana Pelclová², Dorota Groffik, Miroslava Přidalová2, Agnieszka Nawrat-Szołtysik², Aleksandra Kroemeke ${ }^{4}$, Aleš Gába ${ }^{2}$ and Ewa Sadowska-Krępa ${ }^{1}$

\begin{abstract}
Background: The associations between physical activity and metabolic syndrome (MetS) have been mainly found in cross-sectional studies. The aim of this longitudinal study was to examine the relationship between meeting step-based guidelines and changes in the risk of metabolic syndrome.

Methods: This study included data from older women (baseline age $62.9 \pm 4.3$ years) from a 7-year longitudinal study in Central Europe. At baseline and follow-up, physical activity was measured by an accelerometer, and the risk for MetS was assessed according to the NCEP-ATP III criteria. In 59 women, multivariate repeated measures ANOVA was used to compare differences in changes in the risk of MetS in groups based on meeting step-based guidelines (10,000 steps/day and 9000 steps/day for women aged $<65$ and $\geq 65$ years, respectively).

Results: Over 7 years, steps/day increased from 10,944 \pm 3560 to 11,652 \pm 4865 , and the risk of MetS decreased from 41 to $12 \%$ in our sample. Women who longitudinally met step-based guidelines had a significantly higher mean concentration of high-density cholesterol (HDL-C) $(64.5$ and $80.3 \mathrm{mg} / \mathrm{dL}$ at baseline and follow-up, respectively) and a lower concentration of triglycerides (TGs) $(158.3$ and $123.8 \mathrm{mg} / \mathrm{dL}$ at baseline and follow-up, respectively) at follow-up compared to baseline. Moreover, women who increased their daily steps over 7 years to the recommended steps/day value significantly decreased the concentration of TGs $(158.3 \mathrm{mg} / \mathrm{dL}$ and $123.8 \mathrm{mg} / \mathrm{dL}$ at baseline and follow-up, respectively).

Conclusions: Our study might suggest that the long-term meeting of step-based guidelines or an increase in daily steps/day to achieve the recommended value could be related to a lower risk of MetS, specifically in concentrations of HDL-C and TG. These findings may help in designing interventions aiming to decrease the risk of MetS in older women.
\end{abstract}

Keywords: Health, Daily physical activity, Accelerometer, MetS components, Number of steps

\footnotetext{
* Correspondence: i.zajac-gawlak@awf.katowice

${ }^{1}$ Institute of Sport Sciences, The Jerzy Kukuczka Academy of Physical

Education, Katowice, Mikołowska 72A, 40-065 Katowice, Poland

Full list of author information is available at the end of the article
}

(C) The Author(s). 2021 Open Access This article is licensed under a Creative Commons Attribution 4.0 International License, which permits use, sharing, adaptation, distribution and reproduction in any medium or format, as long as you give appropriate credit to the original author(s) and the source, provide a link to the Creative Commons licence, and indicate if changes were made. The images or other third party material in this article are included in the article's Creative Commons licence, unless indicated otherwise in a credit line to the material. If material is not included in the article's Creative Commons licence and your intended use is not permitted by statutory regulation or exceeds the permitted use, you will need to obtain permission directly from the copyright holder. To view a copy of this licence, visit http://creativecommons.org/licenses/by/4.0/ The Creative Commons Public Domain Dedication waiver (http://creativecommons.org/publicdomain/zero/1.0/) applies to the data made available in this article, unless otherwise stated in a credit line to the data. 


\section{Background}

The concomitance of high blood pressure, hyperglycaemia, central obesity, and elevated cholesterol or triglyceride levels, known as metabolic syndrome (MetS), is indicated as one of the major socioeconomic problems faced by the contemporary world [1]. Research shows that MetS increases the risk of type 2 diabetes mellitus and cardiovascular diseases, and its components are among the main causes of death worldwide [2]. An early and accurate diagnosis of MetS enabling the application of effective therapies can therefore be very instrumental in protecting the health and well-being of populations [1]. This is particularly the case in older adults because the risk for MetS increases with age [3].

There is a growing body of evidence that the risk of developing MetS can be reduced by physical activity [4]. While most authors point to moderate-to-vigorous exercise as being much more effective [5] than light-intensity exercise [4], there is general consent that all attempts to quit a sedentary lifestyle can help prevent the development of MetS [6].

Older people, who are the most sedentary within the population [7] and develop MetS the most often [3, 8], are recommended to choose moderate-to-higher intensity exercise such as walking. As a low-impact and affordable form of exercise requiring neither special skills nor equipment [9], walking is very well suited to the needs and physical capabilities of older people. It also has advantages over other sports and recreational activities in that can be easily included in one's daily activities and practised at very old ages [9]. It is also of importance that the increasing availability of step-counting technology makes it possible for people to monitor and regulate their daily physical activity [10].

The authors of a recent systematic review found an inverse relationship between the number of steps taken daily and the presence of MetS [4]. In the case of middle-aged and older adults, it is recommended that they take 10,000 steps per day to prevent the development of MetS [11-14].

Strong associations between the daily number of steps and the risk of MetS development are mostly reported by the authors of cross-sectional studies [15]. Relatively few longitudinal studies have thus far been undertaken to determine relationships between physical activity in older adults and age and their risk of MetS [16].

Given the higher prevalence of MetS in women than men [3] and the lack of longitudinal studies investigating changes in MetS related to physical activity, the aim of this study was to examine the relationship between long-term meetings of step-based guidelines $(10,000$ steps/day and 9000 steps/day for women aged $<65$ and $\geq$ 65 years, respectively) and changes in the risk of MetS in older women. Considering that the risk of MetS can be reduced by physical activity [4], we hypothesized that older women longitudinally meeting the step-based guidelines would have a lower risk of MetS.

\section{Methods \\ Design and participants}

We analysed the data from a longitudinal study in older women from Central European countries, which has been described elsewhere [17]. One hundred and six physically active women aged $60+$ participating in a programme run at the University of Third Age (U3A) were invited to participate in this study. Of those, 51 failed to meet the study inclusion criteria, which required the participants to be able to walk without a prosthetic aid, not use medications for metabolic disorders, and not smoke cigarettes. Therefore, 89 women were assessed during the baseline stage. Over the 7-year period, 2 participants died, 7 had no contact, 5 were ineligible, and 12 refused to participate in the study again.

All the women were informed that their participation was voluntary and that they could withdraw from the study at any time. They provided their written consent for both baseline and follow-up stages.

This study was approved by the Ethics Commission at The Jerzy Kukuczka Academy of Physical Education (reference number. 3/2009). Moreover, an overarching longitudinal study in Central European countries was approved by the Institutional Research Ethics Committee, Faculty of Physical Culture, Palacký University Olomouc (reference number 20/2017).

\section{Biochemical and anthropometric assessments}

Between 8:00 and 10:00 a.m., fasting blood samples were taken from participants, and their systolic/diastolic blood pressure (SDP and DBP, respectively) was measured using a standard mercury sphygmomanometer. The results of two measurements taken at an interval of $15 \mathrm{~min}$ were averaged for analysis. The serum concentrations of glucose, high-density lipoprotein cholesterol (HDL-C), and serum triglycerides (TG) were determined using enzymatic assays and commercially available diagnostic kits (Randox UK, cat. no. GL 2623, CH 200, CH 203, TR 1697). Serum was separated in the usual manner and analysed immediately or kept frozen at $-80^{\circ} \mathrm{C}$ until analysis.

Waist circumference (WC) was determined to the nearest $0.5 \mathrm{~cm}$ using anthropometric tape midway between the lowest rib and the iliac crest in a standing position. The percentages of body fat (PBF) and visceral fat area (VFA) at the umbilical level were determined using an InBody 720 analyser $[18,19]$ according to the manufacturer's instructions (Biospace Co., Ltd., Seoul, Korea). 
The presence of MetS was determined in line with the NCEP/ATP III revised guidelines [20]. According to the guidelines, MetS occurs when three or more of the following criteria are met: (1) WC $\geq 88 \mathrm{~cm}$; (2) TG $\geq 150$ $\mathrm{mg} / \mathrm{dl}$; 3) HDL-C $<50 \mathrm{mg} / \mathrm{dL}$; 4) systolic blood pressure (SBP) $\geq 130 \mathrm{mmHg}$ and diastolic blood pressure (DBP) $\geq 85 \mathrm{mmHg}$; and 5) fasting glucose level $\geq 100 \mathrm{mg} / \mathrm{dl}$.

\section{Physical activity assessment}

At baseline and follow-up, the participants' physical activity (PA) was measured using an accelerometer (ActiGraph GT1M, Manufacturing Technology Inc., FL, USA). The accelerometers were worn by the participants in the small pockets of the elastic belts positioned near the right iliac crest for at least $12 \mathrm{~h}$ each day over a period of 8 days and were only removed for water exercises and before bedtime. The first day's readings were excluded from analysis to ensure that the potential reactivity of participants did not compromise the reliability of measurements [21]. All the participants were instructed to record the duration and type of each physical activity they performed during the day (e.g., walking for $10 \mathrm{~min}$ ).

The time sampling interval of the accelerometers was set at $1 \mathrm{~min}$, an epoch commonly used to measure freeliving physical activity (PA) and in epidemiological research [21], and the step mode was activated. The accelerometer readings were processed in ActiLife v6.13.1 (Pensacola, FL, USA).

\section{Other assessments}

Several self-rated data were obtained from the participants. Smoking status and education level were obtained at both time points. At follow-up, the participants were retrospectively asked about their dietary habits over the 7 years and possible treatment for metabolic disorders.

\section{Data and statistical analysis}

The statistical analysis of the data was performed in STATISTICA 12.5 (StatSoft, USA). The descriptive statistics represent means and their 95\% confidence intervals. Moreover, the numbers and percentages of women meeting the diagnostic criteria for each MetS component and step-based guidelines were calculated for baseline and follow-up. The number of steps/day was selected as a commonly used indicator of physical activity level in adults and older adults [22-25].

To divide women aged $<65$ and $\geq 65$ years into physically highly active (meeting step-based guidelines) and physically low active (not meeting step-based guidelines), threshold values of 10,000 and 9000 steps per day, respectively, were used. The first number was adopted from Bassett et al. [15], Freak-Poli et al. [26], Harris et al. [27], and Tudor-Locke et al. [28], who recommend that adults take at least 10,000 steps per day to stay healthy. For women aged $65+$, it was lowered to account for the likely effect of their age on their activity.

Based on meeting daily step-based guidelines at baseline and follow-up, women were divided into four physical activity groups. Women in the low-low (LL) group were below the recommended step-based thresholds at both baseline and follow-up. Women in the high-low (HL) group reached their step-based thresholds only at baseline and those in the low-high (LH) group only at follow-up. The high-high $(\mathrm{HH})$ group included women who met step-based guidelines at both time points.

Differences between participants' anthropometric parameters, MetS components, and physical activity levels measured in 2009 and 2016, as well as between-group differences in the number of steps, were assessed for statistical significance using a paired t-test. The longitudinal changes in MetS components (the effect of time, $\mathrm{TE}$ ), the between-group differences in MetS components (the effect of physical activity, PAE), and the associations between the groups' physical activity and changes in MetS components (the interaction effect, INT) were assessed by multivariate repeated-measures ANOVA (MANOVA). The effect size was determined by calculating eta squared $(\eta 2)$ as per the following formula: $\eta 2=$ SS effect/SS total, where SS effect is the sum of squares for a given effect and SS total is the total of squares for all effects, interactions, and errors [29]. The 95\% confidence intervals calculated for individual MetS components were also analysed [30, 31].

\section{Results}

Out of 106 older women, the analytical sample consisted of 59 women with a mean baseline age of $62.9 \pm 4.3$ years and baseline BMI of $26.8 \pm 4.2 \mathrm{~kg} / \mathrm{m}^{2}$ at baseline, having tertiary (35.6\%), secondary (59.2\%), and primary (15.2\%) education. The women reported no smoking, no change in their dietary habits and no treatment for metabolic disorders for 7 years. Other sample characteristics for baseline and follow-up are shown in Table 1.

Over 7 years, BMI and PBF significantly increased by 3.2 and $6.3 \%$, respectively, but the risk of MetS decreased from 39 to $12 \%$, and the mean number of criteria for MetS fell by $35.6 \%$. Decreases were also noted in the concentrations of HDL-C and TG, which are MetS risk factors.

Figure 1 and Table 2 show the range of participants meeting different MetS criteria (0-5). Over 7 years, the number of women who met 3 or more criteria for MetS decreased from 24 to 7 . At follow-up, the numbers of participants with elevated TG and BP concentrations and $W C \geq 88 \mathrm{~cm}$ decreased by $50,32.5$, and $36.1 \%$, respectively, but the number of women with raised fasting 
Table 1 Participants' characteristics for baseline and follow-up $(N=59)$

\begin{tabular}{|c|c|c|c|c|c|}
\hline \multirow[t]{2}{*}{ Characteristic } & \multicolumn{2}{|c|}{ Baseline } & \multicolumn{2}{|c|}{ Follow-up } & \multirow{2}{*}{$\begin{array}{l}\text { Difference } \\
\%\end{array}$} \\
\hline & $M$ & $95 \% \mathrm{Cl}$ & $M$ & $95 \% \mathrm{Cl}$ & \\
\hline \multicolumn{6}{|l|}{ Anthropometrics } \\
\hline Height (m) & 158.2 & $(156.9,159.6)$ & 157.3 & $(155.9,158.7)$ & 0.6 \\
\hline Weight (kg) & 67.1 & $(64.4,69.8)$ & 68.0 & $(65.2,70.7)$ & -1.2 \\
\hline $\mathrm{BMI}\left(\mathrm{kg} / \mathrm{m}^{2}\right)$ & 26.8 & $(25.8,27.9)$ & 27.7 & $(26.5,28.8)$ & $3.2^{*}$ \\
\hline VFA $\left(\mathrm{cm}^{2}\right)$ & 133.3 & $(125.2,141,4)$ & 131.0 & $(121.6,140.4)$ & -1.7 \\
\hline PBF (\%) & 36.8 & $(34.9,38.6)$ & 39.1 & $(37.2,40.9)$ & $6.3^{*}$ \\
\hline \multicolumn{6}{|l|}{ Metabolic syndrome } \\
\hline WC (cm) & 84.1 & $(81.2,87.1)$ & 85.1 & $(82.3,87.9)$ & 1.2 \\
\hline Fasting glucose (mg/dL) & 90.3 & $(86.9,93.6)$ & 98.8 & $(95.1,102.5)$ & $9.4^{*}$ \\
\hline $\mathrm{HDL}-\mathrm{C}(\mathrm{mg} / \mathrm{dL})$ & 64.4 & $(60.0,68.8)$ & 76.5 & $(71.6,81.3)$ & $18.8^{*}$ \\
\hline $\mathrm{TG}(\mathrm{mg} / \mathrm{dL})$ & 127.5 & $(115.0,140.0)$ & 106.3 & $(94.9,117.7)$ & $-16.6^{*}$ \\
\hline $\mathrm{SBP}(\mathrm{mmHg})$ & 129.8 & $(125.7,133.9)$ & 135.4 & $(130.3,140.5)$ & 4.3 \\
\hline $\mathrm{DBP}(\mathrm{mmHg})$ & 77.0 & $(74.5,79.6)$ & 79.9 & $(77.1,82.7)$ & 3.8 \\
\hline No. of MetS criteria & 2.2 & $(1.9,2.6)$ & 1.4 & $(1.2,1.7)$ & $-35.6^{*}$ \\
\hline Risk of MetS $(\mathrm{N}, \%)$ & 24 & 40.1 & 7 & 11.8 & $-30.8^{*}$ \\
\hline \multicolumn{6}{|l|}{ Physical activity } \\
\hline Steps/day & 10.944 & $(10.006,11.882)$ & 11,652 & $(10.384,12.920)$ & 6.5 \\
\hline Steps/day aged $<65$ years & 11.596 & $(10.379,12.814)$ & 12.847 & $(11.280,14.414)$ & 10.8 \\
\hline Steps/day aged $\geq 65$ years & 9.673 & $(8.285,11.060)$ & 9.322 & $(7.399,11.244)$ & -3.3 \\
\hline
\end{tabular}

M Mean, 95\% CI Confidence interval, BMI Body mass index, VFA Visceral fat area, PBF Percent body fat, WC Waist circumference, HDL-C High-density lipoprotein cholesterol, TG Triglycerides, SBP Systolic blood pressure, DBP Diastolic blood pressure, MetS Metabolic syndrome

* - statistically significant at $p<.001$

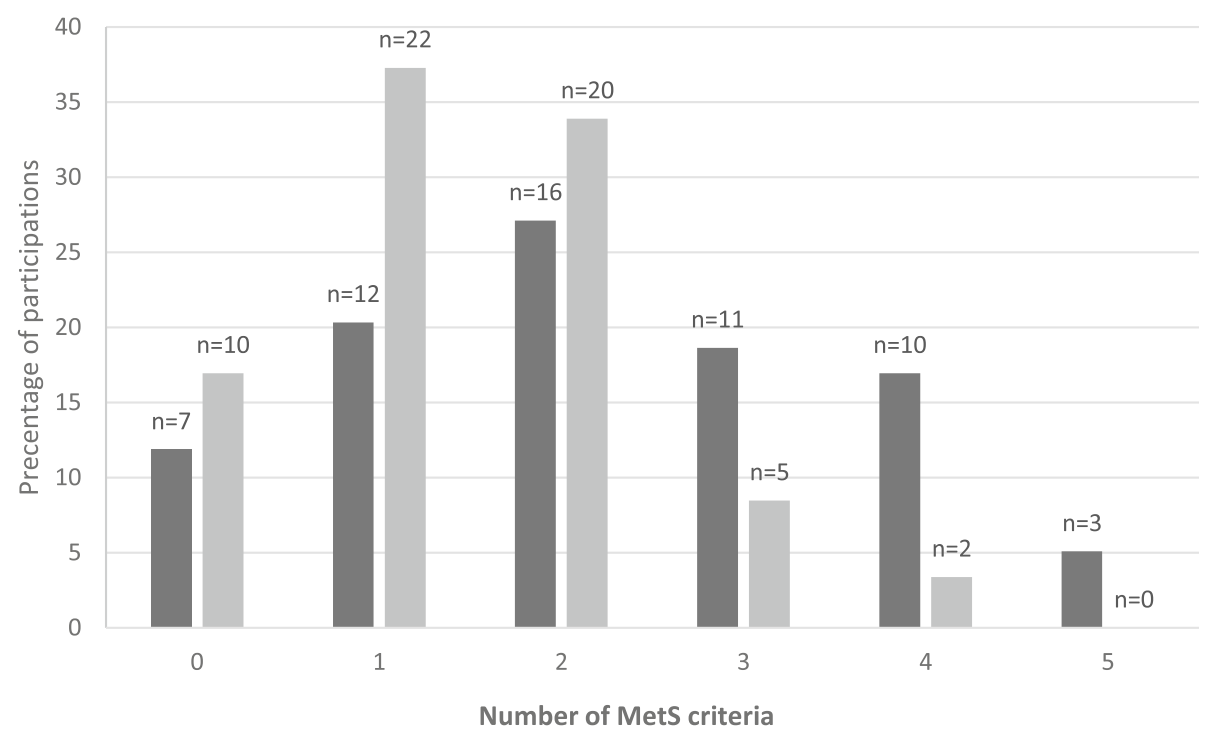

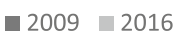

Fig. 1 The numbers of MetS criteria met by participants in baseline (2009) and follow-up (2016) 
Table 2 The numbers and percentages of participants $(N=59)$ who met or did not meet particular MetS criteria in baseline and follow-up

\begin{tabular}{|c|c|c|c|c|}
\hline \multirow{3}{*}{$\begin{array}{l}\text { MetS } \\
\text { component }\end{array}$} & \multicolumn{2}{|c|}{ No. of participants meeting the criterion } & \multicolumn{2}{|c|}{ No. of participants not meeting the criterion } \\
\hline & Baseline & Follow-up & Baseline & Follow-up \\
\hline & $n(\%)$ & $n(\%)$ & $n(\%)$ & $n(\%)$ \\
\hline HDL-C & $25(42.4)$ & $1(1.7)$ & $34(57.6)$ & $58(98.3)$ \\
\hline TG & $16(27.0)$ & $8(13.6)$ & $43(73.0)$ & $51(86.4)$ \\
\hline Fasting glucose & $15(25.5)$ & $23(39.0)$ & $44(74.5)$ & $36(61.0)$ \\
\hline $\mathrm{BP}$ & $40(68.0)$ & $27(46.0)$ & $19(32.0)$ & $32(54.0)$ \\
\hline WC & $36(61.0)$ & $23(39.0)$ & $23(39.0)$ & $36(61.0)$ \\
\hline
\end{tabular}

HDL-C High-density cholesterol, TG Triglycerides, BP Blood pressure, WC Waist circumference

glucose $(<100 \mathrm{mg} / \mathrm{dL})$ increased by $23 \%$. The number of participants with normal HDL-C increased by $58.6 \%$.

Long-term differences in steps/day were not significant. However, it is clear from Table 1 that women increased their mean steps/day by $6.5 \%(10,944$ and 11,652 steps/day at baseline and follow-up, respectively). This was mainly due to an increase in daily steps in women aged $<65$ (11,596 and 12,847 steps/day at baseline and follow-up, respectively).

Table 3 shows 7-year changes in steps/day in different physical activity groups. Groups $\mathrm{LH}$ and $\mathrm{HH}$ significantly increased daily steps $(p=0.002$ and $p=0.04$, respectively), while the HL group significantly decreased steps/day $(p=0.012)$. No change was found for the LL group.

\section{Changes in physical activity and the risk for MetS}

According to MANOVA (Fig. 2a-f), significant changes between baseline and follow-up were found for the concentrations of HDL-C $(F=15.789, p<0.001)$, TG $(F=$ 17.182, $p<0.001)$ and fasting glucose $(F=19.309, p<$ 0.001). The effect of time (TE) was not significant for SBP, DBP, or WC. In follow-up, the HH group and the LH group had significantly higher concentrations of HDL-C than at baseline $(64.5 \mathrm{mg} / \mathrm{dL}$ [CI: $58.8,70.2]$ vs. 80.3 [CI: 73.2, 87.3] and 66.9 [CI: 55.2., 78.6] vs. 79.2 [CI: 73.2, 87.3], respectively). Moreover, the LH group had a significantly decreased concentration of TG $(158.3 \mathrm{mg} / \mathrm{dL}$ [CI: 105.4, 211.2] vs. $123.8 \mathrm{mg} / \mathrm{dL}$ [CI: $82.3,165.4])$. TG decreases in the other three groups were not significant.

All groups had higher levels of fasting glucose in follow-up, but significant changes were noted only in the HH group $(87.6 \mathrm{mg} / \mathrm{dL}$ [CI: $81.9,90.3]$ vs. $95.8 \mathrm{mg} / \mathrm{dL}$ [CI: 99.9, 100.8]) and the LL group $(94.3 \mathrm{mg} / \mathrm{dL}$ [CI: 86.0, 102.7] vs. $107.3 \mathrm{mg} / \mathrm{dL}$ [CI: $94.3,120.3])$. The fasting glucose level in the $\mathrm{HH}$ group was $<100 \mathrm{mg} / \mathrm{dL}$ in both 2009 and 2016.

WC was the only one of the five MetS components that was associated with the levels of participants' physical activity $(F=5.392, p=0.003)$. At baseline, the $\mathrm{HH}$, LH, and HL groups had smaller mean WCs than the LL group. After 7 years, it was still smaller in the groups that had maintained or increased physical activity $(\mathrm{HH}$ and $\mathrm{LH}$ ), but in the HL group, it increased and was similar to the LL group's WC.

The interaction effect of time and physical activity was not significant in any of the MetS criteria.

\section{Discussion}

Our longitudinal study in older women suggests a decreasing risk of MetS in longitudinally active older women. Although the effect of group and time was not significant in any of the MetS criteria, women with

Table 3 Steps/day for different physical activity groups at baseline and follow-up $(N=59)$

\begin{tabular}{|c|c|c|c|c|c|c|c|}
\hline \multirow[t]{3}{*}{ Group $^{a}$} & \multirow[t]{3}{*}{$\mathrm{N}$} & \multicolumn{3}{|c|}{ Baseline } & \multicolumn{3}{|c|}{ Follow-up } \\
\hline & & \multirow{2}{*}{$\begin{array}{l}\text { Age } \\
M\end{array}$} & \multicolumn{2}{|c|}{ Steps/day } & \multirow{2}{*}{$\begin{array}{l}\text { Age } \\
M\end{array}$} & \multicolumn{2}{|c|}{ Steps/day } \\
\hline & & & $M$ & $95 \% \mathrm{Cl}$ & & $M$ & $95 \% \mathrm{Cl}$ \\
\hline $\mathrm{LL}$ & 12 & 66.0 & 7189 & $(6146,8231)$ & 73.0 & 6258 & $(5068,7447)$ \\
\hline $\mathrm{HL}$ & 9 & 64.7 & 11,182 & $(9094,13,269)$ & 71.7 & $7441^{*}$ & $(5797,9084)$ \\
\hline $\mathrm{LH}$ & 10 & 60.8 & 8005 & $(7463,8546)$ & 67.8 & $13247^{*}$ & $(10,538,15,957)$ \\
\hline $\mathrm{HH}$ & 28 & 61.7 & 13,527 & $(12,434,14,621)$ & 68.7 & $14747^{*}$ & $(13,319,16,175)$ \\
\hline
\end{tabular}

$M$ Mean, 95\% Cl Confidence interval

* - statistically significant at $p<0.05$

a $L L$ Low-low group (women not meeting step-based guidelines nor in baseline neither in follow-up), HL High-low group (women meeting step-based guidelines at baseline but not in follow-up), LH Low-high group (women meeting step-based guidelines at follow-up but not in baseline), HH High-high group (women meeting step-based guidelines at both time points) 


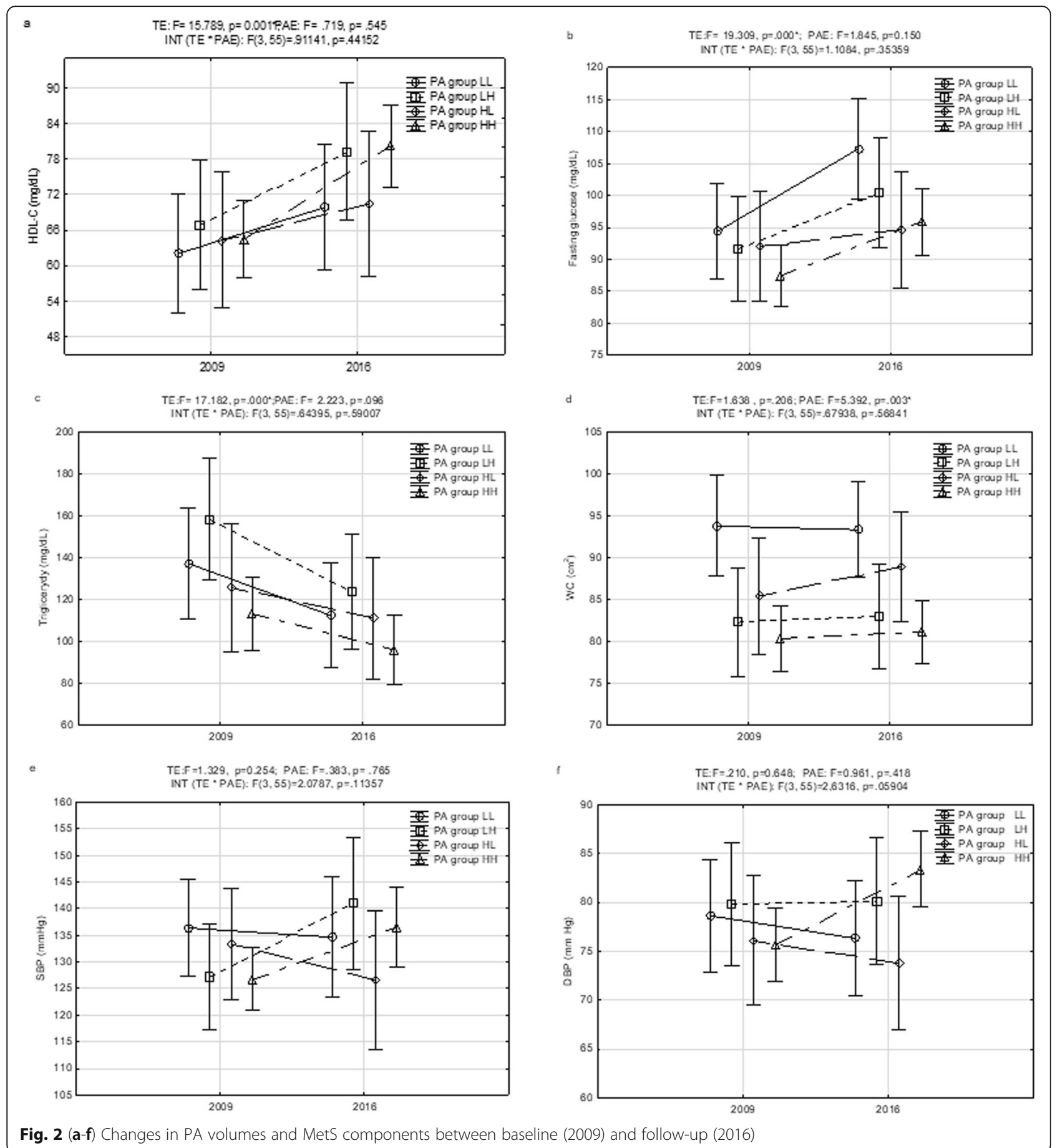

recommended values of steps/day at baseline and follow-up and women who increased their daily steps over 7 years and met the guidelines in follow-up improved their values in several MetS criteria, mainly in concentrations of HDL-C and TG. Conversely, older women longitudinally not meeting the step-based guidelines had risk values of WC at baseline and follow-up and risk values of fasting glucose at baseline.
Looking at the mean values of steps/day at baseline and follow-up and a $6.5 \%$ increase during the 7 year period, our sample consisted of very active women in comparison with the average values of healthy older adults based on normative data [32] and did not support the expected age-related decrease in daily physical activity [33-35]. On the other hand, BMI and PBF significantly increased 
over 7 years, which is in concordance with other longitudinal studies [36, 37].

It should be mentioned that overweight and obesity may lead to metabolic syndrome after menopause [3840], especially in older women [41]. In our sample, the risk of MetS decreased over time, although the average values of BMI and PBF were in the overweight (25-29.9 $\mathrm{kg} / \mathrm{m}^{2}$ ) and obesity (>35\%) categories at baseline and follow-up. However, abdominal obesity indicators, VFA and $\mathrm{WC}$, which did not change, could be stronger predictors of MetS in older women [14, 42].

In this study, we found improvement in HDL-C and TG in the whole sample, but with the largest change in women in the HH group (longitudinally meeting steps/ day guidelines) and in women in the LH group (meeting the guidelines in follow-up). On the other hand, deterioration was found in fasting glucose in the sample, but only women in the LL group (not longitudinally meeting steps/day guidelines) or HL group (not meeting steps guidelines at follow-up) exceeded the risk cut-off point $\geq 100 \mathrm{mg} / \mathrm{dl}$. WC was the highest in the women longitudinally not meeting the step/day recommendation and in women who decreased their steps/day over 7 years. These findings might confirm previous studies suggesting that the risk values of different MetS components can be reduced by exercise and sufficient physical activity [43-46]. Our findings are in line with the USA study [13], suggesting that adults who took more steps/day tended to have lower WC, higher HDL-C, and lower levels of TG. Additionally, a recent review [4] reported a negative association with MetS in all studies assessing step counts.

The strengths of this study are its longitudinal design with a long follow-up duration and objective assessments of physical activity and MetS criteria. The limitations of the study are mainly the relatively small number of participants impeding the generalization of its results and reducing the power of statistical testing. Moreover, the results of the study were not adjusted for dietary information, although the impact of specific food or products on the risk of MetS was suggested in previous studies [47-49]. Additionally, genetic information, family history or comorbidities that could be related to the risk of MetS were not considered in this study. Another limitation lies in the treatment of physical activity. Steps/day were already used in some previous studies, enabling valuable comparison $[4,13]$. However, they did not provide information on the intensity and type of physical activity that might influence the strengths of associations between physical activity and risk of MetS [4].

\section{Conclusion}

Our longitudinal study in a cohort of active older women might suggest that the long-term meeting of step-based guidelines or longitudinal increases in daily steps/day to achieve the recommended value could be related to a lower risk of MetS, specifically in concentrations of HDL-C and TG. These findings may help in designing interventions aiming to decrease the risk of MetS in older women.

\section{Abbreviations}

MetS: Metabolic syndrome; HDL-C: High-density cholesterol; TG: Triglycerides: VFA: Visceral fat accumulation; BMI: Body mass index; PBF: Percent body fat; BP: Blood pressure; DBP: Diastolic blood pressure; SDP: Systolic blood pressure; WC: Waist circumference; PA: Physical activity; 95\% Cl: Confidence interval; TE: The effect of time; PAE: The effect of physical activity; INT: The interaction effect; TE: The effect of time; LL: Low physical activity at baseline (2009) and follow-up (2016); HL: High physical activity at baseline (2009) and low at follow-up (2016); LH: Low physical activity at baseline (2009) and high at follow-up (2016); HH: High physical activity at baseline (2009) and followup (2016)

\section{Acknowledgements}

The authors wish to thank the study participants for their commitment and cooperation. The financial support offered by the Jerzy Kukuczka Academy of Physical Education and the Czech Science Foundation is also gratefully acknowledged.

\section{Authors' contributions}

IZG - study design and supervision, data collection and analysis, manuscript writing; JP - study design and manuscript writing; DG - study design and proofreading of the manuscript; MP - data collection and manuscript proofreading; ANS - data collection and manuscript proofreading; AK - data analysis and manuscript proofreading; AG - data collection and manuscript proofreading; ESK - biochemical blood tests, analysis of their results, and manuscript proofreading. The final version of the manuscript and its publication were unanimously approved.

\section{Funding}

The study was jointly funded by the Czech Science Foundation (research grant No. 18-16423S) and the Jerzy Kukuczka Academy of Physical Education (under statutory funding). The funding sources had no role in the design of the study and did not have any role in collection, analysis, and interpretation of data or in writing the manuscript.

\section{Availability of data and materials}

The dataset analyzed during the current study is available in the Figshare repository, https://figshare.com/articles/dataset/Dataset/13234544.

\section{Ethics approval and consent to participate}

This study was approved by the Ethics Commission at The Jerzy Kukuczka Academy of Physical Education (reference number. 3/2009). Moreover, an overarching longitudinal study in Central European countries was approved by the Institutional Research Ethics Committee, Faculty of Physical Culture, Palacký University Olomouc (reference number 20/2017). and was performed in accordance with the Declaration of Helsinki. All participants agreed in writing to participate in the study. The consent forms are in possession of the authors and can be made available upon request.

\section{Consent for publication}

Not applicable.

\section{Competing interests}

The authors declare no competing interests.

\section{Author details}

${ }^{1}$ Institute of Sport Sciences, The Jerzy Kukuczka Academy of Physical Education, Katowice, Mikołowska 72A, 40-065 Katowice, Poland. ' Faculty of Physical Culture, Palacký University Olomouc, trída Míru 117, 77900

Olomouc, Czech Republic. ${ }^{3}$ Institute of Physioterapy and Health Sciences, The Jerzy Kukuczka Academy of Physical Education, Katowice, Mikołowska 72A, 40-065 Katowice, Poland. ${ }^{4}$ Department of Psychology, SWPS University 
of Social Sciences and Humanities, Chodakowska 19/31, 03-815 Warsaw Poland.

\section{Received: 31 August 2020 Accepted: 9 December 2020} Published online: 06 January 2021

\section{References}

1. O'Neill S, O'Driscoll L. Metabolic syndrome: a closer look at the growing epidemic and its associated pathologies. Obes Rev. 2015;16:1-12.

2. Wilson PWF, D'Agostino RB, Parise H, Sullivan L, Meigs JB. Metabolic syndrome as a precursor of cardiovascular disease and type 2 diabetes mellitus. Circulation. 2005;112:3066-72.

3. Aguilar M, Bhuket T, Torres S, Liu B, Wong RJ. Prevalence of the metabolic syndrome in the United States, 2003-2012. JAMA. 2015;313:1973-4.

4. Amirfaiz S, Shahril MR. Objectively measured physical activity, sedentary behavior, and metabolic syndrome in adults: systematic review of observational evidence. Metab Syndr Relat Disord. 2019;17(1):1-21.

5. Rennie K, McCarthy N, Yazdgerdi S, Marmot M, Brunner E. Association of the metabolic syndrome with both vigorous and moderate physical activity. Int J Epidemiol. 2003:32:600-6.

6. Edwardson CL, Gorely T, Davies MJ, Gray LJ, Khunti K, Wilmot EG, et al. Association of sedentary behaviour with metabolic syndrome: a metaanalysis. PLoS One. 2012;7:e34916

7. Harvey JA, Chastin SFM, Skelton DA. How sedentary are older people? A systematic review of the amount of sedentary behavior. J Aging Phys Act. 2015;23:471-87.

8. Chuang T-J, Huang C-L, Lee C-H, Hsieh C-H, Hung Y-J, Hung C-F, et al. The differences of metabolic syndrome in elderly subgroups: a special focus on young-old, old-old and oldest old. Arch Gerontol Geriatr. 2016;65:92-7.

9. Ogilvie D, Foster CE, Rothnie H, Cavill N, Hamilton V, Fitzsimons CF, et al. Interventions to promote walking: systematic review. BMJ. 2007;334:1204.

10. Tudor-Locke C, Han H, Aguiar EJ, Barreira TV, Schuna JM Jr, Kang M, et al. How fast is fast enough? Walking cadence (steps/min) as a practical estimate of intensity in adults: a narrative review. Br J Sports Med. 2018;52 776-88

11. Cocate PG, de Oliveira A, Hermsdorff HHM, Rita de Cássia GA, Amorim PRS, Longo GZ, et al. Benefits and relationship of steps walked per day to cardiometabolic risk factor in Brazilian middle-aged men. J Sci Med Sport. 2014;17:283-7.

12. Schmidt MD, Cleland VJ, Shaw K, Dwyer T, Venn AJ. Cardiometabolic risk in younger and older adults across an index of ambulatory activity. Am J Prev Med. 2009;37:278-84.

13. Sisson SB, Camhi SM, Church TS, Tudor-Locke C, Johnson WD, Katzmarzyk PT. Accelerometer-determined steps/day and metabolic syndrome. Am J Prev Med. 2010;38:575-82.

14. Zając-Gawlak I, Kłapcińska B, Kroemeke A, Pośpiech D, Pelclová J, Prídalová M. Associations of visceral fat area and physical activity levels with the risk of metabolic syndrome in postmenopausal women. Biogerontology. 2017; 18:357-66.

15. Bassett DR Jr, Toth LP, LaMunion SR, Crouter SE. Step counting: a review of measurement considerations and health-related applications. Sports Med (Auckland, NZ). 2017:47:1303-15.

16. Chen L-J, Lai Y-J, Sun W-J, Fox KR, Chu D, Ku P-W. Associations of exercise, sedentary time and insomnia with metabolic syndrome in Taiwanese older adults: a 1-year follow-up study. Endocr Res. 2015;40:220-6.

17. Cuberek R, Pelclová J, Gába A, Pechová J, Svozilová Z, Príidalová M, et al. Adiposity and changes in movement-related behaviors in older adult women in the context of the built environment: a protocol for a prospective cohort study. BMC Public Health. 2019;19:1-7.

18. Ogawa H, Fujitani K, Tsujinaka T, Imanishi K, Shirakata H, Kantani A, et al. InBody 720 as a new method of evaluating visceral obesity. Hepatogastroenterology. 2011;58:42-4.

19. Park KS, Lee D-H, Lee J, Kim YJ, Jung KY, Kim KM, et al. Comparison between two methods of bioelectrical impedance analyses for accuracy in measuring abdominal visceral fat area. J Diabetes Complicat. 2016;30:343-9.

20. Grundy SM, Brewer HB, Cleeman Jl, Smith SC, Lenfant C. Definition of metabolic syndrome: report of the National Heart, Lung, and Blood Institute/American Heart Association conference on scientific issues related to definition. Circulation. 2004;109:433-8.
21. Esliger DW, Copeland JL, Barnes JD, Tremblay MS. Standardizing and optimizing the use of accelerometer data for free-living physical activity monitoring. J Phys Act Health. 2005;2:366-83.

22. Tudor-Locke C, Bassett DR. How many steps/day are enough? Preliminary pedometer indices for public health. Sports Med. 2004;34:1-8.

23. Choi BCK, Pak AWP, Choi JCL, Choi ECL. Daily step goal of 10,000 steps: a literature review. Clin Invest Med. 2007;30:E146-51.

24. Tudor-Locke C, Hatano Y, Pangrazi RP, Kang M. Revisiting "how many steps are enough?". Med Sci Sports Exerc. 2008;40(7 Suppl):S537-43.

25. Aoyagi Y, Shephard RJ. Habitual physical activity and health in the elderly: the Nakanojo study. Geriatr Gerontol Int. 2010;10(Suppl 1):S236-43.

26. Freak-Poli RLA, Cumpston M, Peeters A, Clemes SA. Workplace pedometer interventions for increasing physical activity. Cochrane Database Syst Rev. 2013:CD009209. https://doi.org/10.1002/14651858.CD009209.pub2.

27. Harris T, Kerry SM, Limb ES, Furness C, Wahlich C, Victor CR, et al. Physical activity levels in adults and older adults 3-4 years after pedometer-based walking interventions: long-term follow-up of participants from two randomised controlled trials in UK primary care. PLoS Med. 2018;15: e1002526.

28. Tudor-Locke C, Craig CL, Brown WJ, Clemes SA, De Cocker K, Giles-Corti B, et al. How many steps/day are enough? For adults. Int J Behav Nutr Phys Act. 2011;8:79.

29. Vacha-Haase T, Thompson B. How to estimate and interpret various effect sizes. J Couns Psychol. 2004;51:473-81.

30. Hopkins WG, Batterham AM, Marshall SW, Hanin J. Progressive statistics. Sport Sci. 2009;41(1):3-13.

31. Shieh $\mathrm{G}$. Confidence intervals and sample size calculations for the weighted eta-squared effect sizes in one-way heteroscedastic ANOVA. Behav Res Methods. 2013;45:25-37.

32. Tudor-Locke C, Craig CL, Aoyagi Y, Bell RC, Croteau KA, De Bourdeaudhuij I, et al. How many steps/day are enough? For older adults and special populations. Int J Behav Nutr Phys Act. 2011;8:80.

33. Doherty A, Jackson D, Hammerla N, Plötz T, Olivier P, Granat MH, et al. Large scale population assessment of physical activity using wrist worn accelerometers: the UK biobank study. PLoS One. 2017;12(2):e0169649.

34. Berkemeyer K, Wijndaele K, White T, Cooper AJM, Luben R, Westgate K, et al. The descriptive epidemiology of accelerometer-measured physical activity in older adults. Int J Behav Nutr Phys Act. 2016;13(1):2.

35. Troiano RP, Berrigan D, Dodd KW, Mâsse LC, Tilert T, McDowell M. Physica activity in the United States measured by accelerometer. Med Sci Sports Exerc. 2008:40:181-8.

36. Hughes VA, Frontera WR, Roubenoff R, Evans WJ, Singh MAF. Longitudinal changes in body composition in older men and women: role of body weight change and physical activity. Am J Clin Nutr. 2002;76(2):473-81.

37. Raguso CA, Kyle U, Kossovsky MP, Roynette C, Paoloni-Giacobino A, Hans D, et al. A 3-year longitudinal study on body composition changes in the elderly: role of physical exercise. Clin Nutr. 2006;25(4):573-80.

38. Carr MC. The emergence of the metabolic syndrome with menopause. Clin Endocrinol Metab. 2003:88:2404-11.

39. Jouyandeh Z, Nayebzadeh F, Qorbani M, Asadi M. Metabolic syndrome and menopause. J Diabetes Metab Disord. 2013;12:1

40. Polotsky HN, Polotsky AJ. Metabolic implications of menopause. Semin Reprod Med. 2010;28:426-34.

41. Pucci G, Alcidi R, Tap L, Battista F, Mattace-Raso F, Schillaci G. Sex-and gender-related prevalence, cardiovascular risk and therapeutic approach in metabolic syndrome: a review of the literature. Pharmacol Res. 2017;120:3442.

42. Kang SH, Cho KH, Park JW, Do JY. Comparison of waist to height ratio and body indices for prediction of metabolic disturbances in the Korean population: the Korean National Health and nutrition examination survey 2008-2011. BMC Endocr Disord. 2015;15:79.

43. Gordon B, Chen S, Durstine JL. The effects of exercise training on the traditional lipid profile and beyond. Curr Sports Med Rep. 2014;13:253-9.

44. Marliss EB, Vranic M. Intense exercise has unique effects on both insulin release and its roles in glucoregulation: implications for diabetes. Diabetes. 2002;51(Suppl 1):S271-83.

45. Durstine JL, Grandjean PW, Davis PG, Ferguson MA, Alderson NL, DuBose KD. Blood lipid and lipoprotein adaptations to exercise: a quantitative analysis. Sports Med (Auckland, NZ). 2001;31:1033-62.

46. Durstine JL, Grandjean PW, Cox CA, Thompson PD. Lipids, lipoproteins, and exercise. J Cardpulm Rehabil. 2002;22:385-98. 
47. Kastorini CM, Milionis HJ, Esposito K, et al. The effect of mediterranean diet on metabolic syndrome and its components: a meta-analysis of 50 studies and 534,906 individuals. J Am Coll Cardiol. 2011;57:1299-313.

48. Sayon-Orea C, Martínez-González MA, Ruiz-Canela M, Bes-Rastrollo M. Associations between yogurt consumption and weight gain and risk of obesity and metabolic syndrome: a systematic review. Adv Nutr. 2017;8(1): 146S-54S.

49. Shin JY, Kim JY, Kang HT, Han KH, Shim JY. Effect of fruits and vegetables on metabolic syndrome: a systematic review and meta-analysis of randomized controlled trials. Int J Food Sci Nutr. 2015;66(4):416-25.

\section{Publisher's Note}

Springer Nature remains neutral with regard to jurisdictional claims in published maps and institutional affiliations.

Ready to submit your research? Choose BMC and benefit from:

- fast, convenient online submission

- thorough peer review by experienced researchers in your field

- rapid publication on acceptance

- support for research data, including large and complex data types

- gold Open Access which fosters wider collaboration and increased citations

- maximum visibility for your research: over $100 \mathrm{M}$ website views per year

At BMC, research is always in progress.

Learn more biomedcentral.com/submissions 